\title{
Evaluation of anthropometric indices, eating habits, and their relationship with CD4 level in individuals with HIV/AIDS
}

\author{
Moradali Zareipour ${ }^{1}$, Ehsan Movahed ${ }^{2}$, Reza Sadeghi ${ }^{3}$, Ahmad Sotoudeh $^{4}$, Saeedeh Sadeghi ${ }^{5}$, \\ Mahboobe Ameri ${ }^{6}$
}

\begin{abstract}
${ }^{1}$ Health Education and Health Promotion, School of Public Health, Urmia Health Center, Urmia University of Medical Sciences, Urmia, Iran

${ }^{2}$ Health Education and Health Promotion, School of Public Health, Jiroft University of Medical Sciences, Jiroft, Iran ${ }^{3}$ Department of Public Health, Sirjan School of Medical Sciences, Sirjan, Iran

${ }^{4}$ Department of Public Health, School of Public Health, Bushehr University of Medical Sciences, Bushehr, Iran

${ }^{5}$ The Social Determinants of Health Research Center (SDHRC), Department of Health Education and Promotion, School of Public Health, Shahid Sadoughi University of Medical Sciences, Yazd, Iran

${ }^{6}$ School of Public Health, Kerman University of Medical Sciences, Kerman, Iran
\end{abstract}

\begin{abstract}
Introduction: Malnutrition is one of the important and complex complications of human immunodeficiency virus (HIV), and anthropometry is a valuable clinical indicator in health planning and policy making among HIV/acquired immunodeficiency syndrome (AIDS) patients. The purpose of this study was to evaluate anthropometric indices, eating habits, and their association with CD4 in individuals with HIV/AIDS.

Material and methods: This descriptive-analytical study was conducted on all individuals with HIV/ AIDS over 20 years of age, who referred to a behavioral diseases counseling center in Iran in 2018. Census sampling method was conducted, and 122 patients were selected. Anthropometric indices were measured using standard methods, and nutritional status questionnaire was used to assess patients' nutritional status.

Results: The mean body mass index in women and men were 25 and $22 \mathrm{~kg} / \mathrm{m} 2$, respectively. Abdominal obesity was 0.89 and $0.87 \mathrm{~cm}$ in female and male patients, respectively. Furthermore, $64 \%$ of patients had poor eating habits. Among food groups, consumption of water $(p=0.05)$ and carbonated drinks ( $p=0.034$ ) were significantly different between men and women. Among dietary groups, only meat and legumes group had a significant association with CD4 level $(p=0.047)$.

Conclusions: Although 57\% of patients with HIV infection were within normal range, abdominal obesity was higher than standard values, and two thirds of the participants presented poor eating habits. Therefore, nutritional interventions are of great importance in this group of patients.
\end{abstract}

HIV AIDS Rev 2020; 19, 4: 237-243

DOI: https://doi.org/10.5114/hivar.2020.101595

Key words: anthropometry, eating habits, HIV/AIDS, CD4.

Address for correspondence: Ehsan Movahed, Health Education and Health Promotion, School of Public Health, Jiroft University of Medical Sciences, Jiroft, Iran, e-mail: ehsanmovahed89@yahoo.com
Article history:

Received: 23.12.2019

Received in revised form: 05.02.2020

Accepted: 20.08.2020

Available online: 30.11 .2020
International Journal of HIV-Related Problems

HIV \& AIDS

R e v i e w 


\section{Introduction}

Acquired immunodeficiency syndrome (AIDS) is considered as a chronic disease [1]. The global number of people infected with human immunodeficiency virus (HIV) and AIDS was 36.9 million by the end of 2016, while the number of new cases in 2017 was reported as 1.8 million. In 2016 in Iran, the number of these patients was estimated as 66 thousand people [2]. This virus is associated with biological and social factors, and changes the individuals' ability to consume foods. These biological and social factors lead to inadequate nutrition, malnutrition, and weight loss, which are among the leading causes of mortality in HIV patients. Weight loss is also an important predictor of death caused by AIDS [3]. For many developing countries, HIV incidence and malnutrition impedes the progress towards achieving the United Nations Millennium Development Goals [4].

Appropriate eating habits include taking a variety of foods at each meal, and this dietary diversity is widely recognized as a valid indicator of diet quality and food safety [5]. Reception and consumption of appropriate foods is of particular importance, but pose a challenge in many countries. For example, in the USA, $15.4 \%$ of the population received inadequate food in 2014 [6]. Studies showed that inappropriate nutrition and malnutrition were associated with increased mortality, augmented incidence of opportunistic infections, decreased adherence to antiretroviral therapy, and poor tolerance to treatment $[7,8]$. Feldman et al. reported that lack of diet adherence and malnutrition increased viral load, lowered CD4 count, and caused HIV-related morbidity and mortality [9]. In this regard, HIV-positive people need $10 \%$ more nutritional energy than healthy people [3], but social consequences, such as stigma, discrimination, and lack of social support have reduced HIV-positive patients' access to appropriate nutrition [10]. In different countries, conflicting results exist regarding the impact of malnutrition on improving immunity at different periods after initiation of drug therapy. Paton et al. also showed that malnutrition reduced the survival rates in HIV-positive patients [11], whereas other studies indicated poor immune responses [12].

Therefore, the quote from William Kelly from the Food and Agriculture Organization may well justify the abovementioned ideas: "Food is not a magic bullet and does not prevent people from deaths caused by AIDS, but it helps the patients to live longer, more comfortable, and better lives" [13].

Protein-energy malnutrition is highly prevalent among HIV/AIDS patients, which in turn, worsens the disease progression by reducing weight, depleting cellular reserves, reducing subcutaneous and arm circumference fat as well as reducing micronutrients, protein, and carbohydrate intake in these patients [4]. In both malnutrition and HIV cases, the number of CD4 and CD8 cells is shown to be decreased [14]. Treatment of HIV-infected patients with antiviral drugs changes the immune system and increases the number of CD4 lymphocytes [15]. However, all patients do not show an optimal response to the treatment. Therefore, to achieve the United Nations Millennium Development Goals, aggressive interventions, such as paying attention to food intake of patients with HIV will prevent the development of HIV. However, few studies have extensively examined the nutritional status and eating habits of people with HIV, and most previous studies have focused on antiviral drugs adherence and clinical outcomes. In this present study, apart from assessing the nutritional status in HIV-positive patients, the relationship between dietary groups and CD4 level was investigated. The purpose of this study was to determine the anthropometric indices, dietary intake, and its association with CD4 level in patients with HIV/AIDS in Kerman City, Iran. These results can be used to determine the current problems, solve them, and design future intervention studies.

\section{Material and methods}

\section{Study design and setting}

This descriptive-analytical study was carried out on individuals with HIV/AIDS over 20 years of age, who referred to a behavioral diseases counseling center, Kerman, Iran in 2018.

\section{Sampling and sample size}

The inclusion criteria for people with HIV were 20 years of age and over, consuming antiviral medication for six months, reading and writing literacy, and willingness to participate in the study. Since the statistical population included 183 members, the census method was used for sampling. A total of 122 people participated in the study, with a response rate of $66.67 \%$.

\section{Instruments and data collection}

To collect the data, two questionnaires were used. The first questionnaire consisted of demographic and clinical information, including age, gender, marital status, educational level, occupation, income level, number of children, CD4 level, stage of the disease, viral load, history of the disease, and body mass index, which were reported in percentage and frequency. To assess the nutritional status in patients, the Iranian food habits questionnaire, designed by Bahrami et al. [16] was applied on 20- to 70-year-old people in Iran in 2014. After retesting of 25 HIV patients, its reliability was reassessed using Cronbach's $\alpha$ of 0.89 , and its validity was confirmed by a panel of nutritionists, infectious specialists, and health educators.

A BMI device was also used to measure the participants' BMI, and a tape measure was applied to measure the hip and abdominal circumferences. Initially, the participants were informed about the dominant dietary habits, such as the type of drink used with food (water $=1$, carbonated drinks $=2$, fruit juice $=3$, buttermilk $=4$, beer $=5$ ), breakfast consumption (yes $=1$, no $=0$ ), cooking method (boiled and 
steamed $=1$, roasted and barbecued $=0$ ), type of consumed oil (olive, sesame, and liquid oil $=1$, vegetable and solid oil, animal, and butter $=0$ ), chicken skin removal (all $=1$, some or no removal $=0$ ), amount of fat in dairy products $(1.5 \%$ low-fat $=1,3 \%$ high-fat $=0)$, salting $($ no $=1$, yes $=0)$, consumption of cake, cookies, chips, and snacks (no $=1$, yes $=0$ ), and consumption of pizza, hamburger, sausage, and kielbasa (no $=1$, yes $=0)$. Later, the participants were asked about the frequency and percentage of consuming fruits and vegetables, dairy, meat and legumes, water, carbonated beverage, and sugar.

In order to complete the questionnaires more precisely, $\$ 2$ was paid to each participant. Later, all questionnaires were collected by a female researcher and assistant. Sampling started at August 23, 2017 and lasted till March 11, 2018.

\section{Ethical consideration}

Ethics committee affiliated with the Yazd University of Medical Sciences approved this study as well as its consent procedure (IR.SSU.SPH.REC 1396.83). Therefore, we made a coordination in order to conduct the study. A cover letter explaining the purpose and procedure of the study was provided to all eligible participants for data collection. Then, verbal agreement of the participants was obtained, and they were ensured about confidentiality of the data and voluntary participation. Also, informed consent forms were obtained after they completed the questionnaires.

\section{Statistical analysis}

Descriptive statistics were used to describe the participants' characteristics and eating habits. $\chi^{2}$ test was applied to determine the frequency of food groups in both genders. Furthermore, SPSS version 25 was used for data analysis.

\section{Results}

A total of 122 patients with HIV/AIDS with an average age of $41.88 \pm 9.46$ years participated in the study. We found that $53.3 \%$ of the participants were male, $46.7 \%$ were married, $36.9 \%$ presented with diploma or higher, $54.1 \%$ were unemployed, $33.6 \%$ had no children, and $41.8 \%$ had an income of more than $60 \$$. According to the results, the disease was transmitted through sexual contact in $37.7 \%$ of cases. The prevalence of emaciation was $10.7 \%$ among the patients, while overweight and obesity had a prevalence rate of $42.6 \%$. CD4 levels were above 350 in 59\% of cases. Of all participants, 93.4\% had HIV. Viral load was less than 100 in $63.9 \%$ of the participants, and $41.8 \%$ of them did not mention risk factors, such as drug abuse (Table 1).

Waist-to-hip ratio is a measurement indicator for abdominal obesity and fat distribution in the body. Here, abdominal obesity was $0.89 \mathrm{~cm}$ in females and $0.87 \mathrm{~cm}$ in males (Table 2).
Table 1. Demographic information of the subjects

\begin{tabular}{|c|c|c|}
\hline Variable & $n$ & $\%$ \\
\hline \multicolumn{3}{|l|}{ Gender } \\
\hline Female & 57 & 46.7 \\
\hline Male & 65 & 53.3 \\
\hline \multicolumn{3}{|l|}{ Marital status } \\
\hline Single & 29 & 28.3 \\
\hline Married & 57 & 46.7 \\
\hline Divorced/widow/widower & 36 & 29.5 \\
\hline \multicolumn{3}{|l|}{ Education } \\
\hline Illiterate & 13 & 10.7 \\
\hline Elementary/middle school & 64 & 52.4 \\
\hline Diploma and higher & 45 & 36.9 \\
\hline \multicolumn{3}{|l|}{ Job } \\
\hline Unemployed & 66 & 54.1 \\
\hline Employed & 56 & 45.9 \\
\hline \multicolumn{3}{|l|}{ Children } \\
\hline 1 & 31 & 25.4 \\
\hline$<2$ & 50 & 41.0 \\
\hline \multicolumn{3}{|l|}{ Income } \\
\hline$<$ US \$ 60 & 71 & 58.2 \\
\hline$>$ US $\$ 60$ & 51 & 41.8 \\
\hline \multicolumn{3}{|l|}{ BMI } \\
\hline$<18.5$ & 13 & 10.7 \\
\hline $18.5-24.9$ & 57 & 46.7 \\
\hline$<24.9$ & 52 & 42.6 \\
\hline \multicolumn{3}{|l|}{ CD4 count } \\
\hline$<100$ & 11 & 9 \\
\hline $101-200$ & 16 & 13.1 \\
\hline $201-350$ & 23 & 18.9 \\
\hline$<350$ & 72 & 59 \\
\hline \multicolumn{3}{|l|}{ Disease stage } \\
\hline HIV & 114 & 93.4 \\
\hline AIDS & 8 & 6.6 \\
\hline \multicolumn{3}{|l|}{ Viral load } \\
\hline$<100$ & 78 & 63.9 \\
\hline 100 and higher & 44 & 36.1 \\
\hline \multicolumn{3}{|l|}{ Disease history } \\
\hline Less than five years & 37 & 30.3 \\
\hline $5-10$ & 37 & 30.3 \\
\hline $10-15$ & 20 & 16.4 \\
\hline 15 and more & 28 & 23.0 \\
\hline
\end{tabular}

Overall, $64 \%$ of the patients presented inappropriate eating habits. The type of drink was appropriate in $73 \%$ of patients, $50.8 \%$ of people ate breakfast, and $82 \%$ of the food items 
Table 2. Mean of anthropometric values in HIV/AIDS patients

\begin{tabular}{l|c|c|c|c|c|c|c}
\hline Gender & $\begin{array}{c}\text { BMI } \\
\left(\mathrm{kg} / \mathrm{m}^{2}\right)\end{array}$ & $\begin{array}{c}\text { Middle arm circumference } \\
(\mathbf{c m})\end{array}$ & $\begin{array}{c}\text { Waist circumference } \\
(\mathbf{c m})\end{array}$ & $\begin{array}{c}\text { Total fat } \\
(\%)\end{array}$ & $\begin{array}{c}\text { Muscle } \\
(\%)\end{array}$ & $\begin{array}{c}\text { Stomach fat } \\
(\%)\end{array}$ & $\begin{array}{c}\text { Hip circumference } \\
(\mathbf{c m})\end{array}$ \\
\hline Female & 25 & 29 & 89 & 34 & 26 & 6 & 100 \\
\hline Male & 22 & 26 & 82 & 17 & 38 & 5 & 94 \\
\hline
\end{tabular}

Table 3. Dietary habits in HIV/AIDS patients

\begin{tabular}{|c|c|c|c|c|}
\hline \multirow{2}{*}{ Variable } & \multicolumn{2}{|c|}{ Appropriate habits } & \multicolumn{2}{|c|}{ Inappropriate habits } \\
\hline & $n(\%)$ & $\mathrm{Cl}$ & $n(\%)$ & $\mathrm{Cl}$ \\
\hline Type of drink with food & $89(73.0)$ & $64.8-80.3$ & $33(27.0)$ & $19.7-35.2$ \\
\hline Eating breakfast & $62(50.8)$ & $42.6-60.7$ & $60(49.2)$ & $39.3-57.4$ \\
\hline Way of cooking foods & $22(18.0)$ & $10.7-25.4$ & $100(82.0)$ & $74.6-89.3$ \\
\hline The type of oil used & $61(50.0)$ & $41.0-59.0$ & $61(50.0)$ & $41.0-59.0$ \\
\hline Skinning chicken & $38(31.1)$ & $23.0-38.5$ & $84(68.9)$ & $61.5-77.0$ \\
\hline Amount of fat in consumed dairy & $27(22.1)$ & $14.8-29.5$ & 95 (77.9) & $70.5-85.2$ \\
\hline Using salt & $38(31.1)$ & $23.8-40.2$ & $84(68.9)$ & $59.8-76.2$ \\
\hline Cakes, cookies, and chips & $13(10.7)$ & $6.2-18.0$ & $109(89.3)$ & $82.0-93.8$ \\
\hline $\begin{array}{l}\text { Hamburgers, sausage, kielbasa, } \\
\text { and pizza }\end{array}$ & $46(37.7)$ & $29.5-46.7$ & $76(62.3)$ & $54.1-70.5$ \\
\hline
\end{tabular}

were fried and grilled. Moreover, $50 \%$ of the participants used animal and solid oils, $68.9 \%$ have never skinned chicken, and $77.9 \%$ did not use high-fat and fat dairy products. Concerning application of salt, the results showed that $68.9 \%$ of the participants used salt at the table. Moreover, $89.3 \%$ of people consumed cakes, cookies, and chips, whereas $62.3 \%$ of people consumed sausage, kielbasa, and pizza (Table 3 ).

Examinations of the food groups between men and women showed that $68.8 \%$ of the participants did not consume or consumed less than one unit of fruit per day. Furthermore, $30.3 \%$ of the participants never consumed vegetables per day. The results showed that $0.8 \%$ of the patients did not use meat. Furthermore, $50.8 \%$ and $30 \%$ of the participants drank carbonated drinks 1-2 and 3-4 times a week, respectively. We found that $27 \%$ of the patients consumed 3 to 4 sugar balls, while $19.7 \%$ eat up 9 sugar balls and more per day. Among the food groups, only water consumption $(p=0.05)$ and carbonated drinks $(p=0.034)$ were significantly different between men and women (Table 4).

$\chi^{2}$ test was applied to study the relationship between food groups and CD4 level. The findings showed a significant association between meat and legumes food group and CD4 level ( $p=0.047)$ (Table 5).

\section{Discussion}

The findings of the study showed that only $36 \%$ of participated patients followed an appropriate diet. Among the food groups, only the meat and legumes group had a significant association with CD4 level, so that $75 \%$ of the par- takers with CD4 of over 350 consumed meat, legumes, and eggs 4 to 5 times or more per week. Martinez et al. [17] investigated patients with cardiovascular diseases and diabetes. They found that $61 \%$ of patients followed a healthy diet. Furthermore, in a study by Nairi et al. [18], more than $50 \%$ of patients with stroke had a good diet. Given the present evidence, HIV-positive patients had poor nutrition, which could be due to the fact that HIV-positive patients suffer from high stigma and discrimination. Therefore, especial attention should be paid to the food reception and diet of HIV-positive patients.

In the present study, $42.6 \%$ of the patients were overweight or obese, but in Mirzaei et al. [19], the prevalence of overweight or obesity in HIV-positive adolescents was 10\%. Tanzania [20] and Ethiopia [21] studies found that $14.9 \%$ and $17.6 \%$ of HIV-positive patients, respectively, were overweight or obese. Rapid urbanization, adoption of carbohydrate and fat diets, and sedentary lifestyle [22] exacerbate the consequences of this disease.

Anthropometric findings showed that weight, waist circumference, hip circumference, and arm circumference were significantly influenced by nutritional behaviors and physical activity. Moreover, body weight and circumference of individuals with regular physical activity and appropriate nutrition were significantly lower than others [23]. Results of our study showed that the rate of abdominal obesity was more than $0.85 \mathrm{~cm}$ in women and men. However, in the study by Azadbakht et al. [24], the abdominal obesity was less than $0.84 \mathrm{~cm}$ in both men and women. In the above-mentioned study, the sample size was 48 , while 122 patients participated 
Table 4. Frequency distribution of people based on the food groups and gender

\begin{tabular}{|c|c|c|c|c|c|c|}
\hline $\begin{array}{l}\text { Type of food } \\
\text { consumed }\end{array}$ & Frequency of food intake & Male, $n(\%)$ & Female, $n(\%)$ & Total, $n(\%)$ & $\begin{array}{c}\text { Test statistics } \\
F\end{array}$ & $p$-value \\
\hline \multirow{4}{*}{ Fruits (daily) } & Never & $24(36.9)$ & $13(22.8)$ & $37(30.3)$ & \multirow{4}{*}{3.03} & \multirow{4}{*}{0.38} \\
\hline & Less than 1 unit & $23(35.4)$ & $24(42.1)$ & $47(38.5)$ & & \\
\hline & 1 unit & $11(16.9)$ & $11(19.3)$ & $22(18)$ & & \\
\hline & $2-3$ units & $7(10.8)$ & $9(15.8)$ & $16(13.1)$ & & \\
\hline \multirow{7}{*}{ Vegetables (daily) } & Never & $21(32.3)$ & $16(28.1)$ & $37(30.3)$ & \multirow{7}{*}{7.30} & \multirow{7}{*}{0.06} \\
\hline & Less than 1 unit & $22(33.8)$ & $16(28.1)$ & $38(31.1)$ & & \\
\hline & 1 unit & $10(15.4)$ & $20(35.1)$ & $30(24.6)$ & & \\
\hline & $2-3$ units & $12(18.5)$ & $5(8.8)$ & $17(13.9)$ & & \\
\hline & 1-2 glasses & $18(27.7)$ & $21(36.8)$ & $39(32)$ & & \\
\hline & 3-4 glasses & $33(50.8)$ & $27(47.4)$ & $60(49.2)$ & & \\
\hline & 5 times and higher & $13(20.0)$ & $8(14)$ & $21(17.2)$ & & \\
\hline \multirow{4}{*}{$\begin{array}{l}\text { Meat, eggs, and } \\
\text { legumes } \\
\text { (weekly) }\end{array}$} & Never & $1(1.5)$ & $0(0)$ & $1(0.8)$ & \multirow{4}{*}{4.40} & \multirow{4}{*}{0.18} \\
\hline & 1 time & $12(18.5)$ & $17(29.8)$ & $29(23.8)$ & & \\
\hline & $2-3$ times & $41(63.1)$ & $27(47.4)$ & $68(55.7)$ & & \\
\hline & 4 times and more & $11(16.9)$ & $13(22.8)$ & $24(19.7)$ & & \\
\hline \multirow{4}{*}{$\begin{array}{l}\text { Water consumption } \\
\text { (daily) }\end{array}$} & Never & $2(3.1)$ & $1(1.8)$ & $3(2.5)$ & \multirow{4}{*}{8.80} & \multirow{4}{*}{0.05} \\
\hline & $1-3$ glasses & $21(32.3)$ & $30(52.6)$ & $51(41.8)$ & & \\
\hline & 4-6 glasses & $30(46.2)$ & $19(33.3) 19$ & $49(40.2)$ & & \\
\hline & 7 glasses and more & $12(18.4)$ & $7(12.3)$ & $19(15.6)$ & & \\
\hline \multirow{4}{*}{$\begin{array}{l}\text { Carbonated drinks } \\
\text { (weekly) }\end{array}$} & Less than 1 time & $12(18.5)$ & $11(19.3)$ & $23(18.9)$ & \multirow{4}{*}{9.60} & \multirow{4}{*}{0.03} \\
\hline & 1-2 times & $26(40.0)$ & $36(63.2)$ & $62(50.8)$ & & \\
\hline & 3-4 times & $15(23.1)$ & $7(12.3)$ & $22(18)$ & & \\
\hline & 5 times and more & $12(18.4)$ & $3(5.3)$ & $15(12.3)$ & & \\
\hline \multirow{5}{*}{$\begin{array}{l}\text { Sugar consumption } \\
\text { (daily) }\end{array}$} & Never & $4(6.2)$ & $8(14)$ & $12(9.8)$ & \multirow{5}{*}{7.80} & \multirow{5}{*}{0.09} \\
\hline & $\begin{array}{c}\text { 1-2 average sized } \\
\text { sugar balls }\end{array}$ & $12(18.5)$ & $16(28.1)$ & $28(23)$ & & \\
\hline & 3-4 sugar balls & $17(26.2)$ & $16(28.1)$ & $33(27)$ & & \\
\hline & 5-8 sugar balls & $14(21.5)$ & $11(19.3)$ & $25(20.5)$ & & \\
\hline & 9 sugar balls and more & $18(27.7)$ & $6(10.5)$ & $24(19.7)$ & & \\
\hline
\end{tabular}

in our research. Possibly, this larger sample size is one of the reasons for a discrepancy between the results. However, HIV-patients should be closely monitored for dietary habits and diversity. According to the dietary guidelines provided by Salvador's Ministry of Health and the World Health Organization for HIV patients, the results found in our study are very critical, because $76 \%$ of our patients consumed hamburgers, sausages, and kielbasa $[25,26]$. Consistent with our results, Martinez et al. conducted a study on HIV-positive patients [18] and found that $84 \%$ of participants consumed sweet drinks, hamburger, sausage, and kielbasa. Deepika investigated HIV-positive patients and showed that although the knowledge level of participants was high with regard to appropriate nutrition, their nutritional performance and eating habits were poor [27]. On the contrary, Luara et al. [28] reported that a 20 to 59-year-old HIV-positive patients presented good eating habits. Family, cultural, and social influences are vital in shaping people's attitudes and beliefs, which affect individuals' interaction with their health behaviors [29].

With regard to the food groups studied in the present research, $30 \%$ and $38.5 \%$ of the patients did not or consumed less than one unit of fruit per day, respectively. However, Martín-Cañavate [25] reported that $61 \%$ of HIV-positive children and adolescents have eaten fruits daily. Discrepancy in the results can be due to the fact that Martín-Cañavate investigated younger people and conducted his study in a different geographical environment. In our study, the consumption of vegetables was also inappropriate among HIV-positive patients; $61 \%$ of them consumed less than one unit of vegetable and $30 \%$ did not eat vegetables. Similar to our study, Martín-Cañavate found that only $28 \%$ 
Table 5. Frequency distribution of people based on meat, egg, and bean food group and CD4

\begin{tabular}{|c|c|c|c|c|c|c|c|}
\hline \multirow{2}{*}{\multicolumn{2}{|c|}{ Parameter }} & \multicolumn{5}{|c|}{ Meat, egg, and bean food group } & \multirow[b]{2}{*}{$p$-value } \\
\hline & & $\begin{array}{l}\text { Never, } \\
n(\%)\end{array}$ & $\begin{array}{c}\text { Once a week, } \\
n(\%)\end{array}$ & $\begin{array}{c}2-3 \text { times a week, } \\
n(\%)\end{array}$ & $\begin{array}{c}\text { 4-5 times a week, } \\
n(\%)\end{array}$ & $\begin{array}{l}\text { Total, } \\
n(\%)\end{array}$ & \\
\hline \multirow{5}{*}{$\begin{array}{l}\text { Dependent } \\
\text { variable } \\
\text { CD4 level }\end{array}$} & $<100$ & $1(100)$ & $1(3.4)$ & $7(10.3)$ & $2(8.3)$ & $11(9) 11$ & \multirow{5}{*}{0.047} \\
\hline & $101-200$ & $0(0)$ & $3(10.3)$ & $11(16.2)$ & $2(8.3)$ & $16(13.1)$ & \\
\hline & $201-350$ & $0(0)$ & $3(10.3)$ & $18(26.5)$ & $2(8.3)$ & $23(18.9)$ & \\
\hline & $<350$ & $0(0)$ & $22(75.9)$ & $32(47.1)$ & $18(75)$ & $72(59)$ & \\
\hline & Total & $1(100)$ & $29(100)$ & $68(100)$ & $24(100)$ & $122(100)$ & \\
\hline
\end{tabular}

of HIV-positive patients consumed vegetables [25]. However, in the study by Mirzaei et al., $52.3 \%$ to $77.3 \%$ of healthy people aged 20-70 years used fruits and vegetables [19]. Studies among healthy people and patients showed that HIV and poverty were two major causes of poor consumption of fruits and vegetables. Numerous studies indicated that bone abnormalities, such as low bone density were particularly at a dire situation among HIV-positive patients, and played an important role in preventing dairy osteoporosis. Dairy consumption in the present study was $20 \%$ higher than that reported by other authors $[30,31]$. Our findings revealed that patients over 20 years of age were more likely to consider dairy consumption, and geographic differences were among other causes of higher dairy consumption.

In the present study, sweet and carbonated drinks were consumed more than 5 times a week in 30\% of the participants, but Martín-Cañavate reported that $84 \%$ of HIV-positive children and teenagers consumed sweet drinks and chocolate more than 3 times a day [25]. Low income was one of the reasons for lower consumption of sweet drinks. However, $67 \%$ of the participants consumed more than 4 sugar balls per day. This rate was also reported by Mirzaei et al., where $37.4 \%$ of healthy participants consumed 4 or more sugar balls per day [19]. In the present study, $68.9 \%$ of patients used saltshaker from the table, which increased the risk of cardiovascular diseases. Consistent with our research, a study on Mexican adolescents showed that sodium intake was high [32]. Poverty, lack of knowledge, and poor economic status of HIV patients can be mentioned as the causes of high salt intake. We found that more weekly intake of meat, legumes, and eggs increased the CD4 level up to above 350. The results reported by Hussen et al. and Engsig et al. [33, 34] were also in agreement with our study. However, these outcomes were not significant among the food groups in a study by Karimi et al. [24]. Application of a validated questionnaire among healthy individuals may not be valid for evaluation among HIV-positive patients. In addition, it can be estimated that increased protein intake is an effective factor in promoting CD4 in HIV-positive patients. The main limitations of this study: 1) data were collected at the time of sanctions against Iran and economic pressure reduced the purchasing power of patients;
2) the study was cross-sectional in nature; 3) self-report tools were used to collect data and the patients may not responded accurately.

\section{Conclusions}

The results of the present study showed that dietary habits in HIV-positive patients are of great concern. Inappropriate dietary habits in $64 \%$ and a prevalence of overweight and obesity in $42.6 \%$ of the patients indicate frequent consumption of high-fat foods and low intake of fruits and vegetables, which causes cardiovascular diseases, stroke, and digestive diseases. Consequently, more accurate and comprehensive nutritional assessments are required in HIV-positive patients, and better nutritional counseling should be provided by caregivers. Health caregivers should seriously follow-up the consumption of local dietary options and their preparation processes to ensure maximum micronutrient intake and appropriate eating habits among these patients.

\section{Acknowledgment}

The authors would like to thank the staffs of a behavioral diseases counseling center in Kerman city.

\section{Conflict of interest}

The authors declare no conflict of interest with respect to the research, authorship, and/or publication of this article.

\section{References}

1. Alfahad TB, Nath A. Update on HIV-associated neurocognitive disorders. Curr Neurol Neurosci Rep 2013; 13: 387.

2. UNAIDS. Ending the AIDS epidemic by 2030. 2018. Available at: http://www.unaids.org/en (Accessed: 6.08.2018).

3. Colecraft E. HIV/AIDS: nutritional implications and impact on human development. Proceed Nutr Soc 2008; 67: 109-113.

4. Karimi I, Kasaeeian N, Atayi B, Tayeri K, Zare M, Azadbakht L. Anthropometric indices and dietary intake in HIV-infected patients. J Isfahan Med Sch 2010; 28: 238-247.

5. Rawat R, Faust E, Maluccio JA, Kadiyala S. The impact of a food assistance program on nutritional status, disease progression, and food security among people living with HIV in Uganda. J Acquir Immune Defic Syndr 2014; 66: e15-e22. 
6. Coleman-Jensen A, Rabbitt MP, Gregory C, Singh A. Household food security in the United States in 2014. United States Department of Agriculture, Washington 2015.

7. Weiser SD, Tsai AC, Gupta R, et al. Food insecurity is associated with morbidity and patterns of healthcare utilization among HIVinfected individuals in a resource-poor setting. AIDS 2012; 26: 67-75.

8. Weiser SD, Young SL, Cohen CR, et al. Conceptual framework for understanding the bidirectional links between food insecurity and HIV/AIDS. Am J Clin Nutr 2011; 94: 1729S-1739S.

9. Feldman MB, Alexy ER, Thomas J, Gambone GF, Irvine MK. The association between food insufficiency and HIV treatment outcomes in a longitudinal analysis of HIV-infected individuals in New York City. J Acquir Immune Defic Syndr 2015; 69: 329-337.

10. Drimie S, Tafesse G, Frayne B. Renewal Ethiopia background paper: HIV/AIDS, food and nutrition security. Washington: International Food Policy Research Institute (IFPRI); 2006.

11. Johannessen A, Naman E, Ngowi BJ, et al. Predictors of mortality in HIV-infected patients starting antiretroviral therapy in a rural hospital in Tanzania. BMC Infect Dis 2008; 8: 52.

12. Paton NI, Sangeetha S, Earnest A, Bellamy R. The impact of malnutrition on survival and the CD4 count response in HIV-infected patients starting antiretroviral therapy. HIV Med 2006; 7: 323-330.

13. Kiefer E, Hoover DR, Shi Q, et al. Association of pre-treatment nutritional status with change in CD4 count after antiretroviral therapy at 6,12 , and 24 months in Rwandan women. PLoS One 2011; 6: e29625.

14. FAO Regional Office for Asia and the Pacific. Take two tablets after the meals, but don't forget the meals: it can help delay the onset of AIDS. Available at: http://wwwfaoorg/world/regional/rap/news_ detailasp?event_id $=25530$ year $=2003$ (Accessed: October 2007).

15. Suttajit M. Advances in nutrition support for quality of life in HIV+/AIDS. Asia Pac J Clin Nutr 2007; 16 Suppl 1: 318-322.

16. Hussen S, Belachew T, Hussien N. Nutritional status and its effect on treatment outcome among HIV infected clients receiving HAART in Ethiopia: a cohort study. AIDS Res Ther 2016; 13: 32.

17. Bahrami D, Mirzaei M, Salehi-Abargouei A. Dietary behaviors of elderly people residing in central Iran: a preliminary report of Yazd Health Study. Elderly Health Journal 2016; 2: 6-13.

18. Martinez H, Palar K, Linnemayr S, et al. Tailored nutrition education and food assistance improve adherence to HIV antiretroviral therapy: evidence from Honduras. AIDS Behav 2014; 18 Suppl 5: S566-577.

19. Mirzaei M, Salehi-Abargouei A, Mirzaei M, Mohsenpour MA. Cohort profile: the Yazd Health Study (YaHS): a population-based study of adults aged 20-70 years (study design and baseline population data). Int J Epidemiol 2018; 47: 697-698h.

20. Sudfeld CR, Isanaka S, Mugusi FM, et al. Weight change at $1 \mathrm{mo}$ of antiretroviral therapy and its association with subsequent mortality, morbidity, and CD4 T cell reconstitution in a Tanzanian HIVinfected adult cohort. Am J Clin Nutr 2013; 97: 1278-1287.

21. Tesfaye DY, Kinde S, Medhin G, et al. Burden of metabolic syndrome among HIV-infected patients in Southern Ethiopia. Diabetes Metab Syndr 2014; 8: 102-107.

22. Owen AL, Suazo CM. Sociodemographic and cultural factors of adult obesity in El Salvador: an exploratory cross-sectional study. J Glob Health 2014; 4.

23. Khosravi S, Amini M, Poursharifi H, Sobhani Z, Sadeghian L. The effectiveness of information-motivation-behavioral model on improving the weight and body size among women undergoing bariatric surgery. Iran South Med J 2018; 21: 81-91.

24. Karimi I, Kasaeeian N, Atayi B, Tayeri K, Zare M, Azadbakht L. Anthropometric indices and dietary intake in HIV-infected patients. J Isfah Med Sch 2010; 28: 238-247.

25. Martín-Cañavate R, Sonego M, Sagrado MJ, et al. Dietary patterns and nutritional status of HIV-infected children and adolescents in El Salvador: a cross-sectional study. PLoS One 2018; 13: e0196380.
26. World Health Organization. Guidelines for an intergrated approach to the nutritional care of HIV-infeced children (6 months14 yrs). WHO 2009; 92.

27. Anand D, Puri S. Nutritional knowledge, attitude, and practices among HIV-positive individuals in India. J Health Popul Nutr 2013; 31: 195-201.

28. Almeida LB, Segurado AC, Duran AC, Jaime PC. Impact of a nutritional counseling program on prevention of HAART-related metabolic and morphologic abnormalities. AIDS Care 2011; 23: 755-763.

29. von Wagner Ch, Knight K, Steptoe A, Wardle J. Functional health literacy and health-promoting behaviour in a national sample of British adults. J Epidemiol Community Health 2007; 61: 1086-1090.

30. Vreeman RC, Scanlon ML, McHenry MS, Nyandiko WM. The physical and psychological effects of HIV infection and its treatment on perinatally HIV-infected children. J Int AIDS Soc 2015; 18 (7 Suppl 6): 20258.

31. de Lima LR, da Silva RC, de Giuliano I, Sakuno T, Brincas SM, de Carvalho AP. Bone mass in children and adolescents infected with human immunodeficiency virus. J Pediatr (Rio J) 2013; 89: 91-99.

32. Mirzaei M, Salehi-Abargouei A, Mirzaei M, Mohsenpour MA. Cohort profile: the Yazd Health Study (YaHS): a population-based study of adults aged 20-70 years (study design and baseline population data). Int J Epidemiol 2018; 47: 697-698h.

33. Hussen S, Belachew T, Hussien NJ. Nutritional status and its effect on treatment outcome among HIV infected clients receiving HAART in Ethiopia: a cohort study. AIDS Res Ther 2016; 13: 32.

34. Engsig FN, Zangerle R, Katsarou O, et al. Long-term mortality in HIV-positive individuals virally suppressed for $>3$ years with incomplete CD4 recovery. Clin Infect Dis 2014; 58: 1312-1321. 